\title{
PENGGUNAAN KALIMAT EFEKTIF DALAM KARYA ILMIAH SISWA: APLIKASI SEMANTIK STUDI KASUS SISWA KELAS XI SMK NEGERI 2 LEMBAH GUMANTI
}

\author{
Dina Ramadhanti \\ Dosen Program Studi Pendidikan Bahasa dan Sastra Indonesia \\ STKIP PGRI Sumatera Barat \\ dina_ramadhanti89@yahoo.com
}

\section{Submitted :23-08-2015, Reviewed:30-08-2015, Accepted:31-10-2015 http://dx.doi.org/10.22202/jg.2015.v1i2.1236}

\begin{abstract}
Abstrak
Artikel ini bertujuan untuk menjelaskan penelitian ini adalah aplikasi semantik dalam pembelajaran bahasa Indonesia terutama dalam penggunaan kalimat efektif. Kalimat tidak efektif, ambigu, redundansi dan ambiguitas dapat mempengaruhi efektivitas hukuman. Metode yang digunakan adalah metode deskriptif untuk menggambarkan kalimat efektif dalam karya ilmiah yang ditulis oleh mahasiswa. Penelitian ini dalam bentuk kata-kata, frase, dan kalimat itu penanda kalimat efektif yang diuraikan dalam pendapat Nasucha. Kalimat efektif melihat dalam komunikasi lisan dan komunikasi tertulis. Kalimat efektif sangat mempengaruhi pembentukan komunikasi antara pembicara dan pendengar. Pelaksanaan rusak kalimat efektif dalam karya ilmiah siswa masih ditemukan. Itu mempengaruhi pemahaman siswa menulis. Kesalahan dalam menerapkan kalimat efektif pada siswa perlu diminimalkan oleh guru bagi siswa untuk menggunakan bahasa dengan baik dalam komunikasi tertulis
\end{abstract}

Kata kunci: Kalimat efektif, karya ilmiah, semantik

\begin{abstract}
This article aims to describe the study was semantic applications in Indonesian learning especially in the use of the effective sentence. The sentence was not effective, ambiguous, redundancy and ambiguity may affect the effectiveness of sentence. The Method used is descriptive method to describe the effective sentence in a scientific papers written by the students. This research in the form of words, phrases, and sentences that was effective sentence markers described in the opinion of Nasucha. The effective sentence noticed in oral communication and written communication. The effective sentence greatly affect the establishment of communication between speakers and listener. The faulty implementation of effective sentence in the scientific work of students still found. It was affect the understanding of students writing. Mistake in applying effective sentence in the students need to be minimized by the teacher for students to use language well in written communication.
\end{abstract}

Keywords: Sentence effective, scientific papers, semantic

PENDAHULUAN

Bahasa adalah alat komunikasi utama bagi manusia. Tanpa bahasa manusia tidak dapat mengkomunikasikan maksudnya kepada sesamanya. Perkembangan teknologi yang semakin canggih juga menuntut manusia untuk tetap menggunakan bahasa baik 
komunikasi lisan maupun tertulis. Untuk dapat menggunakan bahasa dengan baik, manusia dituntut untuk mampu menggunakan bahasa yang tepat serta mudah dipahami. Bahasa dengan susunan kalimat yang baik akan mudah dipahami sehingga terjadi proses pemindahan informasi yang lancar antara pembicara dan pendengar. Informasi dari pembicara akan dapat dimaknai dengan baik oleh lawan bicara apabila pembicara memahami konsep semantik dalam berkomunikasi.

Semantik mengkaji makna satuan bahasa baik kata, frasa, maupun kalimat. Salah satu aspek kajian semantik adalah keambiguitasan, redudansi, dan kerancuan makna. Keambiguitasan adalah kegandaan makna satuan bahasa yang disebabkan oleh struktur gramatikal satuan bahasa sehingga menyebabkan penafsiran ganda bagi pendengar. Redudansi adalah pemakaian satuan bahasa yang berlebihan dalam struktur kalimat. Kerancuan makna adalah makna satuan bahasa yang tidak bisa diterima karena penggabungan satuan bahasa yang tidak lazim (Manaf, 2008:118-122).

Keambiguitasan, redudansi, dan kerancuan makna menyebabkan kalimat tidak efektif. Kalimat yang tidak efektif selain mengganggu kelancaran komunikasi juga akan merusak struktur bahasa. Untuk dapat berkomunikasi dengan baik, maka pembicara harus memperhatikan keefektifan kalimat yang digunakan. Kalimat efektif yang digunakan untuk komunikasi lisan tentu berbeda dengan komunikasi tulis. Susunan kalimat dalam komunikasi tulis kadangkala tidak efektif apabila digunakan untuk komunikasi lisan. Justru kalimat yang digunakan cenderung kaku dan bertele-tele. Untuk itu diperlukan penghayatan yang mendalam mengenai penggunaan kalimat yang efektif baik untuk komunikasi lisan maupun tulisan.

Menurut Akhadiah (2003:116), kalimat efektif adalah kalimat yang benar dan jelas yang akan dengan mudah dipahami orang lain secara tepat. Dengan kata jika suatu kalimat telah dapat menyampaikan maksud penulis dan pembaca memahami maksud penulis maka kalimat tersebut dapat dikatakan telah efektif. Hal ini sejalan dengan pendapat Arifin (1989:70), yang mengatakan bahwa kalimat efektif adalah kalimat yang dapat mewakili gagasan atau pemikiran penulis secara tepat dan dengan sendirinya diterima oleh pembaca sesuai dengan maksud penulisnya.

Akhadiah (2003:116) menyatakan bahwa setiap gagasan, pikiran, atau konsep yang dimiliki seseorang pada praktiknya harus dituangkan ke dalam bentuk kalimat. Kalimat yang baik pada pertama sekali haruslah memenuhi persyaratan gramatikal. Hal ini berarti bahwa kalimat harus disusun berdasarkan kaidah-kaidah yang berlaku seperti unsur-unsur penting yang harus dimiliki setiap kalimat, aturanaturan tentang ejaan yang disempurnakan, dan cara memilih kata dalam kalimat. Agar kalimat yang ditulis dapat memberikan informasi kepada pembaca secara tepat, menurut Akhadiah (2003:116-117) perlu diperhatikan cirri-ciri kalimat efektif yaitu kesepadanan dan kesatuan, kesejajaran bentuk, penekanan dalam kalimat, kehematan dalam mempergunakan kata, dan kevariasian dalam struktur kalimat.

Semi

(2009:218--219) menyatakan bahwa suatu kalimat dikatakan efektif apabila mengandung ciriciri berikut ini. (1) Gramatikal, ditinjau dari aspek tata bahasa sesuai dengan kaidah bahasa Indonesia. (2) Sesuai dengan tuntutan bahasa baku, menggunakan ejaan yang tepat dan menggunakan bahasa baku sesuai tata bahasa. (3) Jelas, kalimat itu dipahami. (4) Ringkas dan lugas serta tidak berbelitbelit. (5) Adanya hubungan yang baik (koherensi) antara satu kalimat dengan kalimat yang lain, antara satu paragraf 
dengan paragraf yang lain. (6) Kalimat harus hidup atau bervariasi dalam hal pilihan kata, urutan kata dalam kalimat, bentuk kalimat, gaya bahasa, perumpamaan dan perbandingan, dan panjang pendeknya kalimat.(7) Tidak ada unsur yang tidak berfungsi dalam kalimat.

Sependapat dengan Semi, Nasucha (2010:22), kalimat dikatakan efektif apabila berhasil menyampaikan pesan, gagasan, perasaan, maupun pemberitahuan sesuai dengan maksud si pembicara atau penulis.Untuk itu penyampaian harus memenuhi syarat sebagai kalimat yang baik, antara lain strukturnya benar, pilihan katanya tepat, hubungan antarbagiannya logis, dan ejaannya pun harus benar. Dalam penulisan kalimat efektif terdapat sebelas pola kesalahan yang harus dihindari agar kalimat yang ditulis efektif dan dapat dipahami pembaca yaitu penggunaan dua kata yang sama artinya dalam sebuah kalimat, penggunaan kata berlebih yang mengganggu struktur kalimat, penggunaan imbuhan yang kacau, kalimat yang tidak selesai, penggunaan kata dengan struktur dan ejaan yang tidak baku, penggunaan tidak tepat kata di mana dan yang mana, penggunaan kata daripada yang tidak tepat, pilihan kata yang tidak tepat, kalimat ambigu yang dapat menimbulkan salah arti, pengulangan kata yang tidak perlu, dan kata kalau yang dipakai secara salah.

Salah satu penerapan kalimat efektif terdapat dalam menulis karya ilmiah sederhana. Karya ilmiah sederhana merupakan salah satu bentuk tulisan yang bersifat nonfiksi. Karya ilmiah sederhana ini harus ditulis dengan bahasa yang baik, susunan kalimat yang efektif, dan mudah dipahami. Dalam karya ilmiah sederhana yang ditulis oleh siswa SMK Negeri 2 Lembah Gumanti khususnya siswa kelas XI Jurusan Teknik Komputer dan Jaringan sering dijumpai kalimat yang tidak efektif, misalkan terdapat redudansi yaitu menggunakan kata yang sama dalam satu kalimat, sehingga membuat kalimat terlihat mubazir dan berbelit-belit. Susunan kalimat yang ditulis siswa menjadikan ide yang disajikan tidak jelas dan sulit dipahami.

Berdasarkan uraian di atas maka artikel ini disusun untuk menjelaskan penggunaan kalimat efektif dan pola-pola kesalahan yang sering dilakukan khususnya bagi penulis pemula seperti siswa tingkat SMK. Pembahasan dilakukan dengan mendeskripsikan permasalahan yang berkaitan dengan analisis penggunaan kalimat efektif yang tidak tepat serta pola-pola kesalahan yang sering dilakukan dalam tugas karya ilmiah sederhana siswa kelas XI Jurusan Teknik Komputer dan Jaringan SMK Negeri 2 Lembah Gumanti. Pembahasan dimulai dengan uraian materi yang berkaitan dengan kalimat efektif. Berdasarkan uraian materi ditentukan teori mana yang digunakan sebagai landasan tinjauan kasus penggunakan kalimat yang tidak efektif. Selanjutnya dilakukan pengkajian lebih lanjut dengan mendaftar penggunaan kalimat yang tidak efektif sesuai dengan teori kemudian ditentukan pola-pola kesalahan yang sering dilakukan. Selanjutnya dilakukan pembahasan kalimat mana yang tidak efektif dan dilakukan perbaikan terhadap kalimat yang tidak efektif itu menjadi kalimat yang efektif. Setelah dilakukan pembahasan lebih lanjut dengan mengklasifikasikan bentuk kesalahan kalimat tidak efektif tersebut dengan menghubungkannya dengan kajian semantik yaitu keambiguitasan, redudansi, dan kerancuan makna.

\section{METODE PENELITIAN}

Penelitian ini merupakan penelitian kualitatif dengan metode deskriptif yang menitikberatkan pada jenis penelitian studi kasus. Moleong (2007:7) menyatakan 
bahwa penelitian kualitatif adalah metode penelitian yang lebih mementingkan proses daripada hasil. Metode deskriptif dilakukan dengan maksud data yang dikumpulkan tidak diolah dengan kata-kata tetapi lebih mengutamakan kedalaman penghayatan terhadap masalah yang dibahas. Data yang dikumpulkan menggunakan analisis isi (content analysis) dengan tujuan untuk menganalisis pola kesalahan penggunakan kalimat efektif dalam tulisan karya ilmiah siswa.

Penelitian ini dilaksanakan di SMK Negeri 2 Lembah Gumanti yang terletak di Jalan Lipek Pageh Salimpek Kecamatan Lembah Gumanti Kabupaten Solok. Data penelitian ini adalah kata, frasa, dan kalimat yang menandakan kalimat efektif. Sumber data adalah tulisan karya ilmiah siswa kelas XI Jurusan Teknik Komputer dan Jaringan yang berjumlah 20 tulisan. Data yang telah diperoleh dianalisis dengan menggunakan langkah-langkah yang dikemukakan oleh Miles dan Huberman (dalam Sugiyono, 2012:337), yaitu reduksi data, penyajian data, dan verifikasi/penarikan kesimpulan.

\section{PEMBAHASAN}

Tinjauan studi kasus pada karya ilmiah siswa kelas XI SMK Negeri 2 Lembah Gumanti berkaitan dengan penggunaan kalimat efektif ini didasarkan pada sebelas pola kesalahan penggunaan kalimat efektif yang dikemukakan oleh Nasucha, yaitu penggunaan dua kata yang sama artinya dalam sebuah kalimat, penggunaan kata berlebih yang mengganggu struktur kalimat, penggunaan imbuhan yang kacau, kalimat yang tidak selesai, penggunaan kata dengan struktur dan ejaan yang tidak baku, penggunaan tidak tepat kata di mana dan yang mana, penggunaan kata daripada yang tidak tepat, pilihan kata yang tidak tepat, kalimat ambigu yang dapat menimbulkan salah arti, pengulangan kata yang tidak perlu, dan kata kalau yang dipakai secara salah.

\section{Penggunaan dua kata yang sama artinya dalam sebuah kalimat}

Penggunaan dua kata yang sama artinya dalam sebuah kalimat terdapat dalam kalimat berikut ini. Memberikan kajian kepada masyarakat berbagai dampak yang dapat timbul dari perkembangan teknologi informasi. Kalimat tersebut salah karena kalimat itu dapat diperbaiki menjadi kalimat yang efektif dengan menghilangkan salah satu kata yang artinya sama yaitu dampak dan timbul serta memperbaiki struktur kalimatnya. Kalimat itu seharusnya berbunyi: Menjelaskan dampak perkembangan teknologi informasi bagi masyarakat

\section{Penggunaan kata berlebih yang mengganggu struktur kalimat}

Penggunaan kata yang berlebih yang mengganggu struktur kalimat terdapat dalam kalimat berikut: Teknologi adalah suatu tubuh dari ilmu pengetahuan dan rekayasa (engineering) yang dapat diaplikasikan pada perancangan produk dan atau proses atau pada penelitian untuk mendapatkan pengetahuan baru.Kalimat tersebut dapat diperbaiki dengan menyusun kembali kalimat dengan menghilangkan beberapa bagian yang dianggap mubazir yang dapat mengganggu struktur kalimat. Kalimat tersebut dapat berbunyi: Teknologi merupakan tubuh ilmu pengetahuan rekayasa yang dapat diaplikasikan pada perancangan produk atau proses penelitian untuk mendapatkan pengetahuan baru.

Kalimat lain dengan kata berlebih yang mengganggu struktur kalimat seperti: Kemudian selain itu mereka juga mengadakan investasi dalam aspek kesehatan masyarakat begitu pula dalam aspek pendidikan. Kalimat tersbut dapat 
diperbaiki menjadi: Selain itu, mereka juga berinvestasi dalam bidang kesehatan dan penddikan masyarakat. Kalimat lain yang menggunakan kata berlebih dan mengganggu struktur kalimat yaitu: Selain memberikan dampak-dampak positif yang sangat banyak, teknologi informasi juga memberikan dampak-dampak negatif. Kalimat tersebut dapat diperbaiki menjadi: Selain memberikan dampak positif, teknologi informasi juga memberikan dampak negatif.

\section{Penggunaan imbuhan yang kacau}

Penggunaan imbuhan yang kacau terdapat dalam kalimat: Dan saat ini, segala aspek kehidupan tersebut telah mampu berkembang dengan pesatnya, perkembangan tersebut beriringan pula dengan perkembangan masyarakat dari masyarakat yang tradisional menjadi masyarakat modern, kemudian secara otomatis perkembangan tersebut menuntut masyarakat menuju ke arah globalisasi.Kalimat tersebut selain menggunakan imbuhan yang kacau juga berbelit-belit karena banyaknya unsur yang sebenarnya tidak diperlukan dalam kalimat. Kalimat itu dapat diperbaiki menjadi: Saat ini perkembangan kehidupan masyarakat dari tradisional ke modern semakin terasa dengan adanya teknologi informasi. Kalimat lain yang menggunakan imbuhan yang kacau yaitu: Dengan mudahnya informasi dapat dicetak ulang tanpa izin dari pemberi informasi atau tanpa menulis sumbernya. Kalimat tersebut dapat diperbaiki menjadi: Informasi dapat dicetak ulang dengan mudah tanpa izin dari pemberi informasi atau tanpa menulis sumbernya.

\section{Kalimat yang tidak selesai}

Kalimat yang tidak selesai terlihat pada kalimat: Munculnya berbagai jenis jejaring sosial dari adanya teknologi informasi. Kalimat tersebut dapat dilengkapi dengan menambahkan unsur lain dalam kalimat sehingga kalimat tersebut berbunyi: Teknologi informasi muncul dengan berbagai jenis jejaring sosial memberikan manfaat bagi generasi muda untuk memperluas pergaulan melalui dunia maya. Selain kalimat tersebut, kalimat yang tidak selesai juga terdapat pada kalimat: Khususnya masyarakat dengan budaya dan adat ketimuran seperti Indonesia. Kalimat tersebut dapat diperbaiki mengubah struktur kalimat dan menambahkan unsur lain sehingga berbunyi: Masyarakat dengan adat dan budaya timur seperti Indonesia dapat memanfaatkan teknologi informasi untuk mengenal budaya dari berbagai belahan dunia.

\section{Penggunaan kata dengan struktur dan ejaan yang tidak baku}

Penggunaan kata dengan struktur dan ejaan yang tidak baku terdapat dalam kalimat: Hyperteks adalah sistim pengkodean yang dikembangkan oleh Vannevar Bush. Kalimat tersebut dapat diperbaiki menjadi: Hyperteks adalah sistem pengkodean yang dikembangkan oleh Vannevar Bush. Kalimat lain yang menggunakan kata dengan struktur dan ejaan yang tidak baku yaitu: Teknologi informasi mampu merubah pola hidup masyarakat. Kalimat tersebut dapat diperbaiki menjadi: Teknologi informasi mampu mengubah pola hidup masyarakat.

\section{Penggunaan kata di mana dan yang mana secara tidak tepat}

Penggunaan kata di mana yang tidak tepat terdapat dalam kalimat: Teknologi informasi juga dapat dimanfaatkan untuk berkreasi, di mana mereka dapat menggunakan berbagai program yang tersedia. Kalimat tersebut dapat diperbaiki menjadi: Teknologi informasi juga dapat dimanfaatkan untuk 
berkreasi dengan menggunakan berbagai program yang tersedia.

\section{Penggunaan kata daripada yang tidak tepat}

Penggunaan kata daripada yang tidak tepat terdapat dalam kalimat: Perkembangan teknologi informasi berawal daripada keinginan masyarakat untuk terus menggunakannya dalam kehidupan sehari-hari.Kalimat tersebut dapat diperbaiki menjadi: Perkembangan teknologi informasi dimulai dari keinginan masyarakat untuk menggunakannya dalam kehidupan sehari-hari.

\section{Pilihan kata yang tidak tepat}

Pilihan kata yang tidak tepat terdapat dalam kalimat: Dan diakui atau tidak, perlahan-lahan mulai mengubah pola hidup dan pola pemikiran masyarakat khususnya masyarakat pedesaan dengan segala image yang menjadi ciri khas mereka.Kalimat tersebut akan efektif apabila dihilangkan kata-kata yang tidak perlu dan mengganti pilihan kata yang salah. Kalimat tersebut akan berbunyi: Diakui atau tidak, teknologi informasi mengubah pola hidup dan pola pikir masyarakat khususnya masyarakat pedesaan dengan segala pandangan yang menjadi ciri khasnya. Pilihan kata yang salah juga terdapat dalam kalimat: Meningkatkan pengetahuan masyarakat tentang proses perkembangan teknologi informasi yang sedang berlangsung dalam masyarakat. Kalimat tersebut dapat diperbaiki menjadi kalimat yang efektif sehingga berbunyi: Peningkatan pengetahuan masyarakat tentang teknologi informasi yang berkembang di tengah masyarakat perlu dilakukan.

Kalimat ambigu yang dapat
menimbulkan salah arti
Kalimat ambigu yang dapat
menimbulkan salah arti terdapat dalam

kalimat: Mesin kasir memanfaatkan teknologi komputer sehingga memberi kumudahan dalam perhitungan. Kalimat tersebut dapat diperbaiki menjadi: Mesin kasir dengan teknologi komputer memberikan kemudahan dalam perhitungan.

\section{Pengulangan kata yang tidak perlu}

Pengulangan kata yang tidak perlu terdapat dalam kalimat: Dari manfaat yang didapatkan, teknologi informasi mulai digunakan dan diterapkan untuk membantu operasional dalam proses bisnis dengan pemanfaatan teknologi informasi. Kalimat tersebut diperbaiki menjadi: Teknologi informasi dapat dimanfaatkan untuk membantu operasional dan proses bisnis.

\section{Kata kalau yang dipakai secara salah.}

Kata kalau yang dipakai secara salah terdapat dalam kalimat: Teknologi informasi kalau digunakan tidak sesuai dengan tempatnya akan memberikan dampak yang negatif bagi penggunanya. Kalimat tersebut dapat diperbaiki menjadi kalimat yang efektif sehingga berbunyi: Teknologi informasi apabila digunakan tidak pada waktunya akan memberikan pengaruh yang negatif bagi penggunanya.

Pembahasan pola kesalahan kalimat efektif di atas memperlihatkan bahwa kalimat menjadi tidak efektif karena adanya keambiguitasan, redudansi, dan kerancuan makna. Dari ketiga hal tersebut, redudansi lebih sering dilakukan siswa. Redudansi diartikan sebagai pemakaian satuan bahasa yang berlebihan dalam struktur kalimat. Berdasarkan sebelas pola kesalahan penulisan kalimat efektif yang dikemukakan oleh Nasucha, maka kesalahan yang tergolong redudansi adalah penggunaan dua kata yang sama artinya dalam sebuah kalimat, penggunaan kata yang berlebih yang menggangu 
struktur kalimat, kalimat ambigu yang dapat menimbulkan salah arti, pengulangan kata yang tidak perlu.

\section{Simpulan}

Kalimat efektif adalah kalimat yang jelas dan memenuhi kriteria dan kaidah baik komunikasi tulis maupun komunikasi lisan. Kalimat efektif untuk komunikasi lisan dan komunikasi tulis berbeda dari segi penggunaan. Pada komunikasi tulis lebih ditekankan pada penggunaan kalimat yang sesuai dengan tata bahasa dan kaidah yang baik dan benar, sedangkam pada komunikasi lisan kalimat dikatakan efektif apabila pendengar mudah memahami apa yang disampaikan pembicara. Pola kesalahan penerapan kalimat efektif dalam komunikasi tulis menurut Nasucha terdiri atas sebelas macam yaitu penggunaan dua kata yang sama artinya dalam sebuah kalimat, penggunaan kata berlebih yang mengganggu struktur kalimat, penggunaan imbuhan yang kacau, kalimat yang tidak selesai, penggunaan kata dengan struktur dan ejaan yang tidak baku, penggunaan tidak tepat kata di mana dan yang mana, penggunaan kata daripada yang tidak tepat, pilihan kata yang tidak tepat, kalimat ambigu yang dapat menimbulkan salah arti, pengulangan kata yang tidak perlu, dan kata kalau yang dipakai secara salah.

Berdasarkan analisis studi kasus yang dilakukan pada tulisan karya ilmiah siswa kelas XI Jurusan Teknik Komputer dan Jaringan SMK Negeri 2 Lembah Gumanti, banyak ditemukan kesalahankesalahan penulisan kalimat. Kesalahan itu nerujung pada ketidakefektifan kalimat sehingga pembaca sulit memahami maksud penulis. Hal ini menunjukkan bahwa kemampuan siswa masih rendah dan perlu dilakukan bimbingan lebih lanjut terhadap siswa menginngat siswa akan sering menulis karya ilmiah hingga tamat sekolah nanti. Guru bahasa Indonesia di sekolah perlu menumbuhkembangkan kebiasaan menulis siswa agar siswa terbiasa menulis dan mampu menerapka kaidah tata bahasa tulis dalam kalimatnya. Selain itu sekolah juga dapat mengembangkan kegiatan ekstrakurikuler dalam bidang tulis-menulis untuk mendorong siswa terbiasa menulis.

\section{DAFTAR PUSTAKA}

Akhadiah, Sabarti, dkk. 2003. Pembinaan Kemampuan Menulis Bahasa Indonesia. Jakarta: Erlangga.

Moleong, Lexy J. 2002. Metodologi Penelitian Kualitatif. Bandung: Rosdakarya.

Nasucha, Yakub. dkk. 2010. Bahasa Indonesia untuk Penulisan Karya Ilmiah. Yogyakarta: Media Perkasa.

Semi, Atar. 2009. Menulis Efektif. Padang: UNP Press.

Sugiyono. 2012. Metode Penelitian Kuantitatif, Kualitatif, dan $R \& D$. Bandung: Alfabeta. 